\title{
O CONCEITO GREGO DE NATUREZA
}

NADDAF, Gerard. The greek concept of nature. Albany: State University of New York Press, 2005.

Marcelo P. Marques* marquess56@yahoo.com.br

O presente estudo sobre o conceito grego de natureza, desenvolvido pelo pesquisador canadense Gerard Naddaf, é o desdobramento de um trabalho mais amplo, publicado em 1992, L'origine et l'évolution du concept grec de phusis, que o autor decidiu aprofundar e detalhar em três etapas, sendo o presente livro a primeira delas. Os dois próximos volumes serão Plato and the peri phúseos tradition e Living in conformity with nature (cujo foco será Aristóteles e a tradição helenística). A opção por uma perspectiva histórica de pesquisa se justifica, segundo o autor, pela riqueza de fontes, primárias e secundárias, assim como pela complexidade da própria temática da natureza, que, de fato, fica evidente nas inúmeras controvérsias das quais tem sido objeto, ao longo dos séculos.

O livro de Naddaf tem como motivo propulsor a tentativa de esclarecer a passagem do livro X das Leis de Platão, no qual o Estrangeiro de Atenas critica as concepções de natureza de todos os que escreveram peri phúseos. Segundo o autor, essa crítica se justificaria por eles nunca terem admitido a noção de "intenção" (implícita na noção de tékhne) na explicação do universo, o que estaria na base do "ateísmo" da época. Permito-me lembrar que, no Timeu de

* Professor do Departamento de Filosofia, FAFICH - UFMG, Belo Horizonte, Brasil.

KRITERION, Belo Horizonte, no 116, Dez/2007, p. 505-509. 
Platão, essa questão se resolve "miticamente", ou seja, através de um relato que é chamado de eikós múthos ou discurso verossímil (um discurso no qual há uma prevalência do registro da semelhança, típica da representação imagética - Timeu 29D2, 59D6 etc.). Através de uma grandiosa imagem narrativa, Timeu propõe que o mundo foi produzido por um artesão divino (demiourgós) que, tendo no horizonte as formas inteligíveis, infunde inteligibilidade no receptáculo (khóra) ou material do qual é feito o universo. Essa mistura resultaria no melhor arranjo cósmico possível, no qual a Inteligência (noûs) das leis da geometria imposta à Necessidade (anánke) resultaria num mundo ordenado e belo, ou seja, a natureza (phúsis) tal como a conhecemos e na qual está incluída também a pólis. Na medida em que os pensadores da natureza anteriores a Platão não postulam um tal deus inteligente, no início de tudo, eles seriam passíveis de serem criticados por ateísmo.

Naddaf pretende reconstruir o movimento de pensamento que levou Platão a formular e tentar resolver o problema do modo como o faz; por isso retoma as principais representações míticas e teorias filosóficas que, de um modo ou de outro, explicam a phúsis. Desde Hesíodo, os autores seguem um esquema em três partes, na medida em que elaboram a compreensão das coisas através da busca da origem do universo, do ser humano e da comunidade política, ou seja, cosmogonia, antropogonia e politogonia articulam-se para dar conta da totalidade da natureza. Segundo Platão, para Hesíodo, por exemplo, os deuses surgiriam depois do universo, sendo que, no relato de Timeu, a divindade está presente desde o início. De qualquer modo, investigar a phúsis significa explicar o presente, ou o universo em seu estado atual, tal como o conhecemos hoje.

Vejamos a estrutura do livro em questão. No capítulo 1, é feita uma pesquisa sobre o sentido de "natureza", através de um estudo etimológico e da análise de alguns textos fundamentais (na sua maioria, traduzidos pelo próprio autor): Odisséia X, Heráclito, alguns tratados hipocráticos, um fragmento de Eurípides, Xenofonte, Aristóteles e, finalmente, o livro X das Leis de Platão. O termo phúsis suscita diferentes camadas de significação - crescimento de algo, matéria primordial (ou origem), processo e resultado - que o autor vai articular numa concepção unificada, também através da análise das diferentes abordagens dos especialistas (Burnet, Gigon, Jaeger, Heidel, Kahn, Barnes, entre outros). É difícil resolver se o título historía perí phúseos, aplicado aos escritos dos diferentes pensadores, foi de fato utilizado já pelos ditos présocráticos, mas é certo que foi empregado no período Alexandrino, para designar uma pesquisa sobre a origem e o desenvolvimento do mundo, do começo até hoje. 
O texto platônico (Leis X 889A et seq.) critica a concepção segundo a qual a ordem do universo seria estabelecida por natureza ou por acaso (phúsin kai túkhen), uma ordem na qual a arte (tékhne) teria um papel secundário. Os primeiros elementos seriam privados de vida ou sem alma (ápsukhon) e moverse-iam arbitrariamente, devido a combinações aleatórias, ou seja, não através do intelecto (ou dià noûn) (que Naddaf traduz, com Saunders, por intelligent planning), nem através de algum deus, mas simplesmente por natureza e por acaso. É curioso observar que Naddaf (assim como a tradução francesa de Diès) introduz o termo criação, inexistente no original grego (creations of art / les créations les plus grandes). A arte teria nascido depois (a tékhne é um ser mortal, produto de mortais), incluindo a política e a legislação, cujas determinações não seriam verdadeiras. Essa visão das coisas seria imposta por homens supostamente sábios aos jovens, de modo que a impiedade acabaria por tomar conta, e prevaleceria a noção de que os deuses não são como a lei (ou o costume) prescreve que sejam. Isso explicaria as revoltas (stáseis) e o modo de vida relacionado, que consiste em dominar os outros e não em servi-los. Nessa concepção criticada pelo Estrangeiro de Atenas, a natureza seria a matéria primordial, ou seja, os elementos que, movidos por uma suposta causalidade espontânea, geram (ou movem), por sua vez, todas as coisas, segundo seus próprios poderes, sem a postulação de uma inteligência produtora, enquanto tal.

No capítulo 2, são analisadas as concepções implícitas nos mitos cosmogônicos, considerados como antecedentes importantes dos tratados peri phúseos. $\mathrm{O}$ autor apresenta uma noção de mito perfeitamente sintonizada com a reflexão de autores contemporâneos (como Calame, Burkert, Eliade e Nagy, entre outros), passa rapidamente pelo poema cosmogônico (épico) babilônico Enuma elish, provavelmente do século XII a.C., para se concentrar nos poemas de Hesíodo - a Teogonia e os Trabalhos e os dias -, que analisa de modo original e instigante, ao valorizar o contexto histórico de sua produção. Os poemas cosmogônicos e antropogônicos são associados às circunstâncias políticas de renovação e manutenção do poder na cidade. Na Teogonia e nos Trabalhos e os dias, diferentes grupos sociais encontram expressão poética e, digamos, ideológica, com seus respectivos valores e concepções de excelência. O poema sobre a natureza - do cosmo e dos homens -, ao se desvincular da dimensão performativa dos rituais, encontra continuidade na pesquisa cada vez mais racional da natureza, expressa nos escritos dos filósofos pré-socráticos.

Todo o Capítulo 3 é dedicado a Anaximando de Mileto (610-546 a.C.), considerado o primeiro relato racional, em prosa, do tipo peri phúseos. A análise de Naddaf renova e enriquece de modo decisivamente original a 
compreensão do filósofo jônico, ao recuperar as informações dos fragmentos doxográficos, sob o crivo da confrontação dos argumentos dos diferentes críticos especializados. Ele encontra um equilíbrio bastante convincente entre a conjetura especulativa e a convergência de dados historiográficos, para propor, de modo meticuloso, um pensamento articulado e surpreendentemente diversificado. No âmbito de uma investigação filosófica sobre a natureza das coisas (historía peri phúseos), Anaxágoras proporia causas racionais e naturais, já separando, de algum modo, a dimensão cosmológica da antropológica. Naddaf passa pela discussão do ápeiron como arkhé, levando em conta tanto a fonte aristotélica como a análise lingüística do termo; apresenta a cosmologia, com a descrição do surgimento e desenvolvimento dos opostos, a constituição dos círculos das estrelas, da Lua e do Sol, em volta da Terra; discute suas fontes prováveis - mítica, astronômica, arquitetônica e política -, mantendo a possibilidade de convivência das diferentes ordens de fatores, mas priorizando a dimensão política do pensamento filosófico emergente. Discute, ainda, as relações entre isonomia política e natureza, entre cosmologia e ordem social, entre os seres humanos e os animais, a formação da comunidade humana e, finalmente, as relações da civilização jônica com a cultura egípcia, a partir dos testemunhos de Heródoto e Hecateu. O capítulo culmina com a apresentação do mapa elaborado por Anaximandro, a primeira imagem geográfica do ecúmeno grego, que sintetiza cosmologia, geografia e política em uma filosofia tipicamente da natureza, ou seja, na qual o termo phúsis é compreendido como o processo de surgimento e de desenvolvimento da totalidade dos seres até o momento presente.

O capítulo 4 vai de Xenófanes aos Atomistas, num grande panorama das pesquisas pré-socráticas sobre a natureza: Xenófanes de Colofon, Pitágoras e os pitagóricos, Heráclito, Parmênides, Empédocles, Anaxágoras, Leucipo e Demócrito. $\mathrm{O}$ autor apresenta cada um dos filósofos, expõe suas posições filosóficas sobre a natureza dos seres, no cosmo e na comunidade humana, levando em conta os textos, com rigor e originalidade analítica, numa profusão impressionante de fontes, tanto antigas como modernas. Todas as afirmações e opções hermenêuticas são sustentadas, seja por referências textuais, seja pela confrontação dos argumentos dos diferentes comentadores.

O livro apresenta 50 páginas de Notas, nas quais não só o autor dá as referências, mas também discute as posições contrastantes; uma Bibliografia extensa, atual e extremamente útil para o pesquisador em filosofia présocrática, além dos Índices, um de Conceitos e de Nomes próprios e o outro das Passagens clássicas citadas. 
Sua conclusão retoma a questão inicial, pondera os resultados obtidos de fato e inicia uma discussão com os poetas (Aristófanes e Ésquilo), que mais anuncia os desdobramentos da pesquisa (previstos para o próximo livro) do que efetivamente avalia o papel das pesquisas do tipo historía perì phúseos na reação do Platão das Leis.

Fica a questão inicial, a saber, se a pesquisa efetivamente desenvolvida no livro, para além de seus méritos inerentes, é o melhor caminho para interpretarmos a crítica ao ateísmo, nas Leis, ou se a posição platônica deve ser esclarecida através dos referenciais internos ao pensamento do próprio Platão. De um modo geral, considero discutível a necessidade de se fazer um percurso histórico para esclarecer um problema claramente interno à filosofia dos diálogos. A meu ver, as concepções platônicas de intelecto (noûs) e do deus artesão (demiourgós) não se deixam traduzir facilmente por "intenção inteligente", tanto se levarmos em conta a psicologia da República, reiterada no Timeu, como se refletirmos sobre a noção de eikós mûthos que designa o estatuto do discurso cosmológico platônico. Historicamente falando, o mito cosmológico platônico não se opõe linearmente às pesquisas pré-platônicas sobre a natureza. A oposição (apontada no livro X das Leis) é um construto de Platão, que, mais uma vez, fabrica uma versão dos pensadores que lhe são anteriores, para melhor destacar sua própria posição.

Observo, também, a desigualdade do tratamento dado aos pré-socráticos, em geral. O capítulo 4, que repassa os diversos filósofos, mesmo sendo extremamente informativo, serve mais para levantar problemas do que para aprofundá-los. Talvez a decisão se justifique pelo próprio recorte global do livro; o detalhe com que é tratada a visão de Anaximandro acaba por compensar a generalidade com que são tratados os outros autores.

De qualquer modo, os méritos da pesquisa apresentada são muitos: tratase de interpretações originais dos diversos autores estudados, de um exemplo de rigor metodológico a ser seguido, de uma referência atualizada das fontes, antigas e modernas, de valor inestimável. Em suma, o livro de Naddaf propicia ótima leitura, tanto pela leveza da redação, como pelo ritmo argumentativo, que transforma as discussões eruditas e minuciosas em reflexão instrutiva e estimulante. 